\title{
Stiff Skin Syndrome
}

National Cancer Institute

\section{Source}

National Cancer Institute. Stiff Skin Syndrome. NCI Thesaurus. Code C118636.

A rare, autosomal dominant inherited syndrome caused by mutations in the FBN1 gene.

It is characterized by hard and thickened skin, usually over the entire body, and limited joint motility. 